\title{
Utilization of Optical Character Recognition (OCR) in the Development of a Number System Converter Application
}

Niel Francis B. Casillano

Department of Information Technology, Eastern Samar State University Philippines; nfcasillano@gmail.com

\section{Abstract}

Objectives: This study focused on integrating Optical Character Recognition (OCR) in the development of a Number System Converter Android application. The primary goal of the study was to read the written or printed text either in decimal, binary, hexadecimal and octal and convert it to the desired number system. Methods: The Rapid Application Development methodology was employed in the development of the system. Findings: The expert testing resulted in a grand mean of 4.77, interpreted as strongly acceptable. This means that the expert evaluators were able to use the system with ease and was easily able to convert text to the desired number system successfully. Applications/Improvements: The successful development of the application will immensely help students to easily convert a value from one number system to another.

Keywords: Android, Mobile Technology, Number System, ISO, OCR

\section{Introduction}

Information technology has revolutionized and transformed how people deal with the economy, business, politics, education, religion, and many other fields. Every day more and more innovations are developed with the primary aim to provide convenience with the way people learn and communicate ${ }^{1}$. One of the major breakthroughs that made a huge impact in many fields is the development of mobile and wireless technology. One of the fields that have been greatly impacted by mobile technology is the academe. This started the shift of many educational institutions from a traditional setting to a mobile learning setting.

One of the emerging technologies that are being utilized by many mobile application developers is the OCR. OCR is the mechanical or electronic conversion of images of typed, handwritten or printed text into machine-encoded text, whether from a scanned document, a photo of a document, a scene-photo or from subtitle text superimposed on an image ${ }^{2}$. It is widely used as a form of information entry from printed paper data records, whether passport documents, invoices, bank statements, computerized receipts, business cards, mail, printouts of static-data or any suitable documentation.

Meanwhile, one of the most cognitively challenging topics in computer science is the topic on number system conversion. Number system conversion involves converting a value from one base to another other (e.g. decimal to octal, decimal to binaryf5 and vice versa). All number systems are interconvertable, each having a different method to be converted ${ }^{3}$. The long conversion methods become very tedious for beginners making it hard for them to understand and surpass the number system conversion topic ${ }^{4}$.

The mobile technology revolution and the OCR technology have prompted the researcher to develop a mobile application that utilized the capabilities of Optical Character Recognition. The application served as an automated number converter but instead of typing the data the application was integrated with a camera that reads a handwritten text and automatically converts it to 
the desired number system (either decimal, binary, octal or hexadecimal).

\section{Objectives of the Study}

This study primarily aimed to integrate OCR in the development of an Android-based Number System Converter Application. Specifically, this study aimed to:

1. Develop and integrate the following features:

a. A module for choosing the base number system to the desired number system.

b. A component for capturing written text.

c. A module for showing the converted value.

2. Conduct an Expert Testing using a modified questionnaire based on ISO 9126 Software Quality Metrics ${ }^{5}$.

\section{Software Development Methodology}

The development of the system adapted the Rapid Application Development (RAD) model. Rapid application development is a software methodology which provides a faster development and does not compromise the quality of the software ${ }^{6}$.As shown in Figure 1, RAD is divided into three major stages: (1) requirements planning; (2) system design; and (3) system implementation ${ }^{7,8}$.

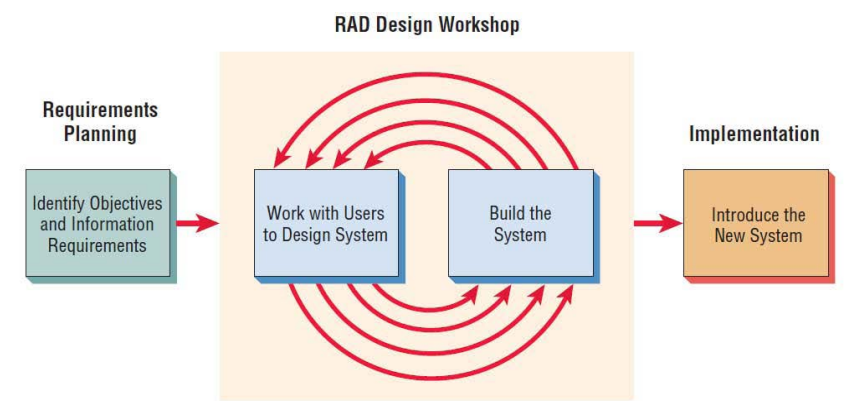

Figure 1. Rapid application design framework ${ }^{7}$.

\subsection{Requirement Planning Phase}

The developers conducted on-site observations and interviews to be familiar with the transactions of the manual system and assess the needs of the users. System requirements were then identified to fit the needs of the users.

\subsection{RAD Design Workshop Phase}

The developers developed module designs and integrate them into a functional system. The module designs and functions were updated depending on the user responses. The process was done over and over until a refined version of the system was developed.

\subsection{Implementation Phase}

The refined versions were then tested by the end-user/ clients for final quality check and final implementation is carried out once the system adheres to the end-users' standards.

Figure 2 shows the different capabilities of the application. As shown in the use case diagram, the user can open the application, choose the desired number system and ultimately capture the written value; the application will then automatically convert the captured value and display the final output.

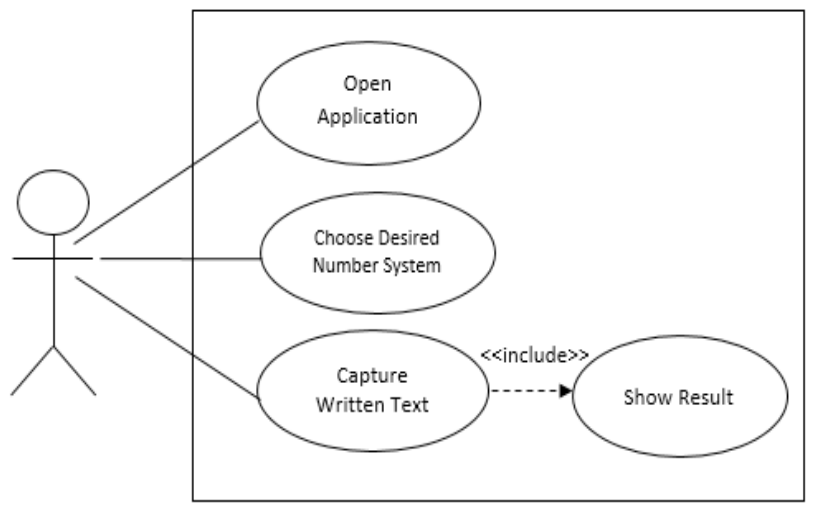

Figure 2. Use case diagram for the number system application.

\subsection{Design Requirements}

As shown in Figure 3, the different steps in optical character recognition are as follows:

1. First step in OCR is the Scanning of images and converts it to its corresponding digital value. This process is called text digitization

2. Pre-processing is the application of different algorithms and techniques to make raw data more usable.

3. Noise Detection and Correction is the removal of unwanted data from the converted images and text to ensure that a more usable digital data is captured.

4. Sometimes during the image conversion, digitized data is skewed; this is why skew detection and correction is employed to fix image angles.

5. The primary aim of layout analysis is to divide the raw image into non-text areas and "text lines"-sub-images 
of the original image that each contains a linear arrangement of symbols in the target language.

6. Characters are then divided into arcs, circles, and other geometric figures and are compared to a known character.

7. Finally, neural networks, decision trees, and other algorithms are employed to produce the actual value of the character.

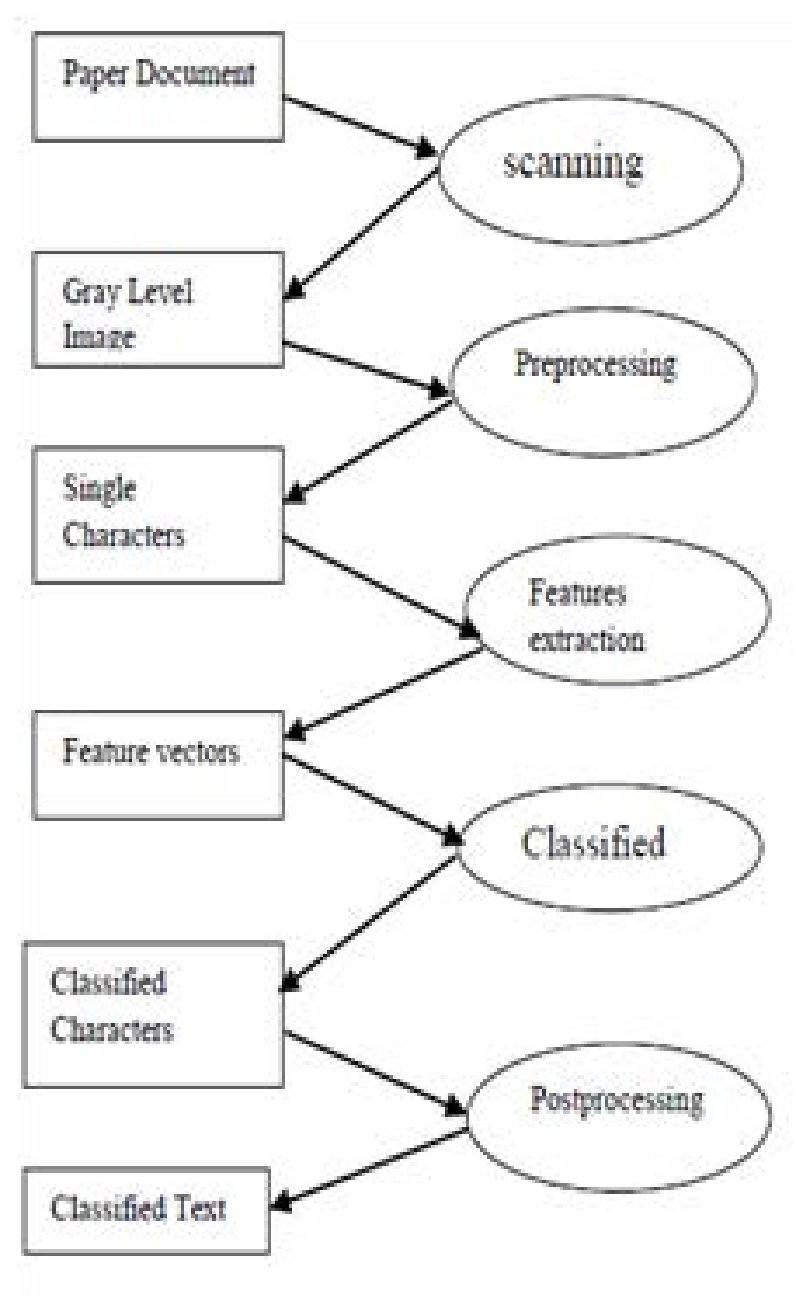

Figure 3. Steps of OCR $\stackrel{8}{\text {. }}$

\section{Software Evaluation}

The questionnaire that was used to evaluate the system is based on ISO 9126 standards. ISO 9126 serves as a framework or model for providing worldwide acceptable software qualities required for software evaluation. Under this standard, software must possess six main qualities namely: Functionality, Maintainability, Efficiency, Reliability, Portability and Usability. (ISO, 1991). The experts were chosen because of their strong proficiency on the field of mobile computing technology. The experts were faculty members who handled subjects related to android technology, java application development and web applet development.

\section{Results and Discussion}

After undergoing the different phases of development and software evaluation under the RAD model, the following results were obtained:

\subsection{Interface Design}

Figure 4 shows the homo form for the application. The user can choose whether to convert a value from decimal (base 10) to binary (base 2), octal (base 8), and hexadecimal (base 16).

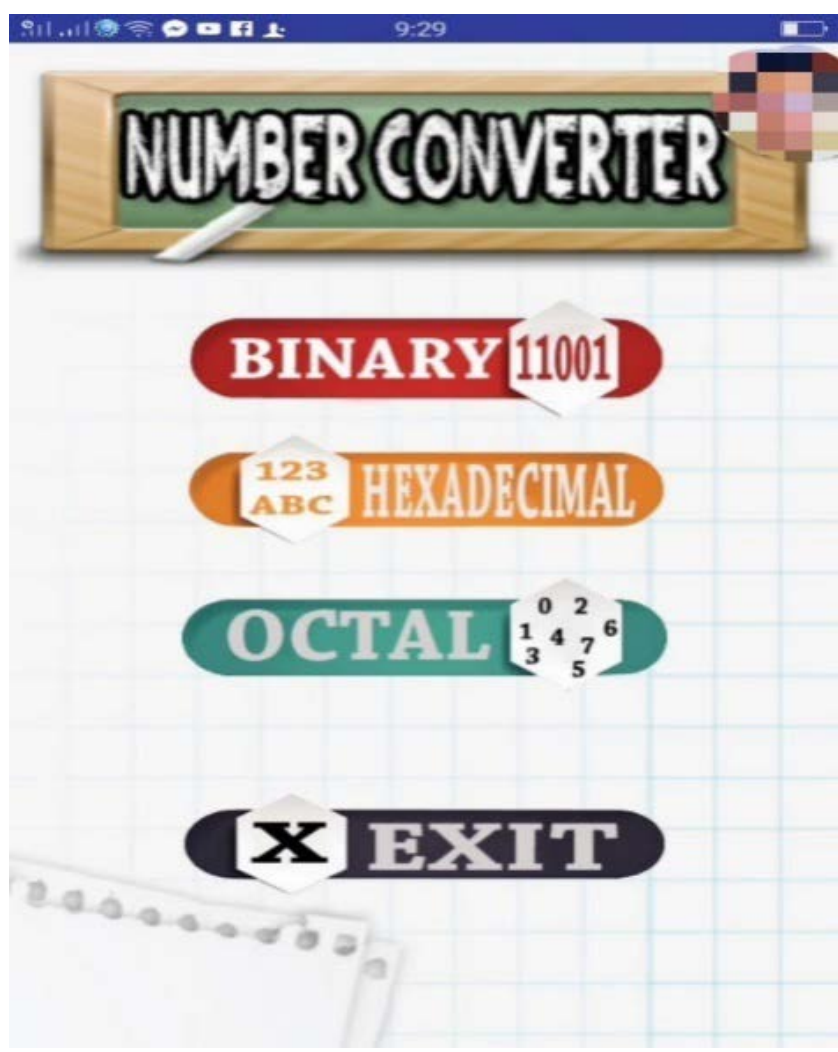

Figure 4. Number system converter home screen

Figure 5 shows the interface for converting binary (base 2) to decimal (base 10) and vice versa. The interface contains a camera module where the user will point the mobile phone's camera to the written decimal or binary value and convert it to the chosen number system. 
Table 1. Mean and interpretation for parameter functionality

\begin{tabular}{|l|l|l|l|l|}
\hline \multicolumn{7}{|c|}{ Questions } & $\begin{array}{c}\text { Frequency } \\
\text { (Yes) }\end{array}$ & $\begin{array}{c}\text { Percentage } \\
\text { (Yes) }\end{array}$ & $\begin{array}{c}\text { Frequency } \\
\text { (No) }\end{array}$ & $\begin{array}{c}\text { Percentage } \\
\text { (No) }\end{array}$ \\
\hline $\begin{array}{l}\text { A module for choosing the base number } \\
\text { system to the desired number system. }\end{array}$ & 15 & $100 \%$ & 0 & - \\
\hline A component for capturing written text. & 15 & $100 \%$ & 0 & - \\
\hline $\begin{array}{l}\text { A module for showing the converted } \\
\text { value. }\end{array}$ & 15 & $100 \%$ & 0 & - \\
\hline
\end{tabular}

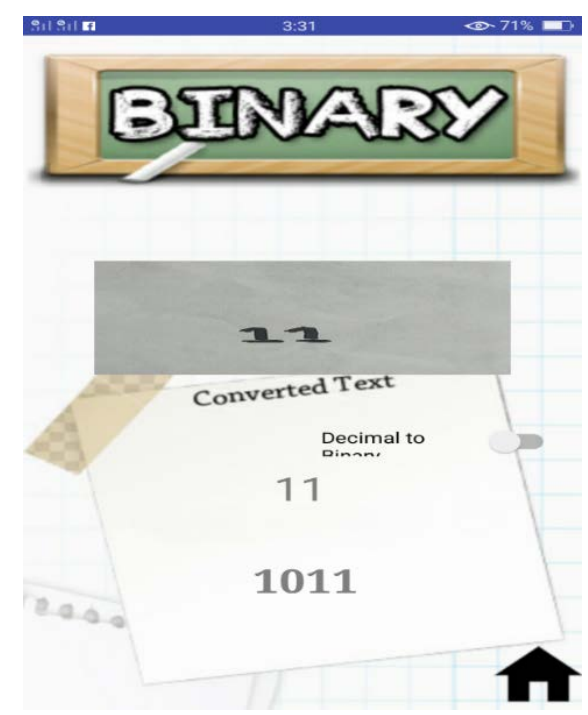

Figure 5. Binary to decimal and decimal to binary conversion screen.

\subsection{Expert Testing}

Table 1 shows that all experts answered yes $(n=15,100 \%)$ to all items under the parameter functionality. This means that all components needed by the end-user/client are present in the mobile application. This also means that the system has fully adhered to the standards of ISO in terms of functionality.

Table 2 shows a grand mean of 4.91 interpreted as strongly acceptable. All five subparameters were rated as strongly acceptable (understand ability; learn ability, operability, attractiveness, usability compliance). This result implies that the mobile system is indeed usable. The mobile system can easily be manoeuvred and all its components and operations. Its basic design also made the system learnable and user-friendly. The same data also entails that the mobile system adhered to the standards of ISO in terms of Usability.
Table 2. Mean and interpretation for parameter usability

\begin{tabular}{|l|l|l|}
\hline \multicolumn{3}{|c|}{ Usability } \\
\hline \multicolumn{1}{|c|}{ Sub parameter } & \multicolumn{1}{c|}{ Mean } & \multicolumn{1}{c|}{ Interpretation } \\
\hline Understand ability & 5.00 & Strongly Acceptable \\
\hline Learn ability & 5.00 & Strongly Acceptable \\
\hline Operability & 4.92 & Strongly Acceptable \\
\hline Attractiveness & 4.92 & Strongly Acceptable \\
\hline Usability compliance & 4.69 & Strongly Acceptable \\
\hline Grand Mean & $\mathbf{4 . 9 1}$ & Strongly Acceptable \\
\hline
\end{tabular}

Table 3 shows a grand mean of $\mathbf{4 . 6 3}$ interpreted as strongly acceptable. All three subparameters were rated as strongly acceptable (Time behavior, Resource Utilization, and Efficiency Compliance). This result implies that the mobile system is efficient in terms of delivering results and handling data. This also means that the mobile system fully adhered to the ISO standards in term of Efficiency.

Table 3. Mean and interpretation for parameter efficiency

\begin{tabular}{|l|l|l|l|}
\hline $\begin{array}{l}\text { ISO 9126 Major } \\
\text { Parameters }\end{array}$ & $\begin{array}{l}\text { Weighed } \\
\text { Mean }\end{array}$ & Interpretation & Rank \\
\hline Functionality & - & & \\
\hline Efficiency & 4.63 & $\begin{array}{l}\text { Strongly } \\
\text { Acceptable }\end{array}$ & 2 \\
\hline Usability & 4.91 & $\begin{array}{l}\text { Strongly } \\
\text { Acceptable }\end{array}$ & 1 \\
\hline Grand Mean & $\mathbf{4 . 7 7}$ & $\begin{array}{l}\text { Strongly } \\
\text { Acceptable }\end{array}$ & \\
\hline
\end{tabular}

Table 4 shows us an overall mean of 4.77 interpreted as strongly acceptable. The parameter Functionality, as shown in Table 1, shows that all the needed requirements 
based on the requirements analysis were all met; this is evident with the full agreement of all expert testers. The major parameters (Efficiency and Usability) were rated by the pool of experts as Strongly Acceptable. The different parameters were ranked based on the weighted mean to determine the best parameter the mobile system has and based on table 4 that best feature the system is its Usability. Although the mobile system was deemed strongly acceptable improvements can be made so that all parameters will have a perfect rating and for the mobile system to be more resistant to errors and bugs. Overall, the system has adhered to the quality standards of ISO 9126.

Table 4. Grand mean for all parameters

\begin{tabular}{|l|l|l|}
\hline \multicolumn{3}{|c|}{ Efficiency } \\
\hline \multicolumn{1}{|c|}{ Sub parameter } & \multicolumn{1}{|c|}{ Mean } & \multicolumn{1}{c|}{ Interpretation } \\
\hline Time behaviour & 4.77 & Strongly Acceptable \\
\hline Resource Utilization & 4.56 & Strongly Acceptable \\
\hline Efficiency compliance & 4.55 & Strongly Acceptable \\
\hline Grand Mean & $\mathbf{4 . 6 3}$ & Strongly Acceptable \\
\hline
\end{tabular}

\section{Conclusions}

Based on the System Development and Expert Testing, the following conclusions were drawn:

1. The following features were successfully developed and integrated into the system, as per results reflected on table 1:

a. A module for choosing the base number system to the desired number system.

b. A component for capturing written text.

c. A module for showing the converted value.

2. The Expert Testing resulted in a grand mean of 4.77 , interpreted as strongly acceptable. This means that the system adhered to all sub-parameters under the major parameters Efficiency and Usability. Furthermore, improvements in the overall design and fault tolerance are recommended to improve the results of the expert testing.

\section{References}

1. Dotong C, De Castro E, Dolot J, Prenda M. Barriers for educational technology integration in contemporary classroom environment. Asia Pacific Journal of Education, Arts and Sciences. 2016; 3(2):13-20.

2. Gosavi M, Pund I, Jadhav H, Gedam S. Mobile application with optical character recognition using neural network. Journal of Computer Science and Information Technology. 2015; 4(1):483-9.

3. Latif S, Ullah R, Jan H. A step towards an easy inter conversion of various number systems. arXiv preprint arXiv:1107.1663. 2011.

4. Latif S, Qayyum J, Lal M, Khan F. Novel approach to the learning of various number systems. International Journal of Computer Applications. 2011; 7(4):18-28. https://doi.org/10.5120/3116-4283

5. ISO. ISO/IEC FDIS 9126-1: Software Engineering - Product Quality -Part 1: Quality Model. Geneva, Switzerland: International Standardization Organization; 2001.

6. Naz R, Khan M. Rapid applications development techniques: A critical review. International Journal of Software Engineering and its Applications; 2015. p. 163-76. https://doi.org/10.14257/ijseia.2015.9.11.15

7. Kendall KE, Kendall JE. Systems analysis and design. 8th Edition. New Jersey: Pearson Education, Inc.; 2011. p. $1-601$.

8. Sharma A, Jha SK. Identification of alphanumeric pattern usingandroid.International JournalonRecentandInnovation Trends in Computing and Communication. 2015; 3(4):1-5. https://doi.org/10.17762/ijritcc2321-8169.1504149 